\title{
Psychometric properties of questionnaires evaluating health-related quality of life and functional status in polytrauma patients with lower extremity injury
}

\author{
Lian Jansen 1,2, Martijn PM Steultjens²,3, Herman R Holtslag4 ${ }^{4}$, Gert Kwakkel² and Joost Dekker²
}

\begin{abstract}
Background: Long term disability is common among polytrauma patients. However, as yet little information exists on how to adequately measure functional status and health-related quality of life following polytrauma.

Aims: To establish the unidimensionality, internal consistency and validity of two health-related quality of life measures and one functional status questionnaire among polytrauma patients.

Methods: 186 Patients with severe polytrauma including lower extremity injury completed the Sickness Impact Profile-136 (SIP-136), the Medical Outcomes Study 36-Item Short Health Survey (SF-36) and the Groningen Activity Restriction Scale (GARS) 15 months after injury. Unidimensionality and internal consistency was assessed by principal components analysis and Cronbach's alpha (a). To test the construct validity of the questionnaires, predetermined hypotheses were tested.
\end{abstract}

Results: The unidimensionality and internal consistency of the GARS and the SF-36, but not the SIP-136 were supported. The construct validity of the SF-36, GARS and to a lesser extent the SIP-136 was confirmed.

Conclusion: The SF-36 and the GARS appear to be preferable for use in polytrauma patients over the SIP-136.

\section{Introduction}

People who sustain traumatic injury do not generally regain their pre-injury levels of physical functioning and experience difficulty in performing activities of daily living (ADL) [1,2]. Previous studies have suggested that the lower extremities are the most frequently injured body regions in polytrauma patients [3]. In addition, injuries of the lower extremities are believed to have a major impact on functional status and health-related quality of life (HRQoL) [3,4].

The Sickness Impact Profile-136 (SIP-136) [5] and the Medical Outcomes Study 36-Item Short Health Survey (SF-36) [6] are widely used measures of HRQoL and have been used in populations with a wide range of diagnoses and disease severity including trauma care $[1,2]$. The

* Correspondence: martijn.steultjens@gcal.ac.uk

2 Department of Rehabilitation Medicine and EMGO Institute, VU University Medical Centre, Amsterdam, The Netherlands

Full list of author information is available at the end of the article
Groningen Activity Restriction Scale (GARS) $[7,8]$ is a questionnaire, which measures patient's functional limitations of socially defined roles and tasks and is used in various countries in different populations. However, any instrument that is used to assess patients should have adequate psychometric properties and be appropriate for the patient population assessed. The reliability and validity of these questionnaires in trauma patients has not yet been established.

The aim of the present study was to investigate: 1) the unidimensionality, 2) internal consistency and 3) construct validity of the SIP-136, SF-36 and GARS among polytrauma patients with at least one injury of the lower extremity.

\section{Materials and methods Participants}

The present study used data from a large prospective cohort study designed to examine multiple outcomes 
after traumatic injury [9]. Four hundred and ninety-nine consecutive severely injured patients who entered and stayed in the Hospital were considered for participation in this study. From this group, children below the age of 16 years $(n=40)$ were excluded, as were patients who died before the final assessment of outcome $(n=100)$. Of the 359 eligible patients, 335 gave informed consent and participated in the prospective cohort study. Twenty-four patients were lost to follow-up. Reasons for withdrawal from the study were: three lived abroad, seven addresses were untraceable, eleven patients withdrew their consent and three had an incomplete dataset.

For the present study patients were included if they had: 1) a fracture or injury of the lower extremity (including pelvis) with a Hospital Trauma Index (HTI) [10] of two or more, 2) an Injury Severity Score (ISS) of 16 or above and 3) age of 17 years or older and 4) were able to write and read Dutch. Individuals that had suffered spinal cord injury were excluded. This resulted in 186 patients being included in the analyses for the present study.

\section{Measures}

Approximately 15 months after injury, patients completed the SIP-136, SF-36 and GARS.

The SF-36 [6] includes 36 multiple-choice items and takes approximately five to ten minutes to complete. The SF-36 is grouped into eight subscales scores: Physical and Social Functioning, Role Limitations due to Physical Health and Emotional Problems, Mental Health, Bodily Pain, Vitality and General Health. All raw scale scores are linearly converted to a 0 to 100 scale, with higher score indicating higher levels of functioning or well-being.

The SIP-136 [5] is a standardized questionnaire consisting of 136 (yes/no) statements about health-related dysfunction. The 136 items are grouped into 12 different categories: Ambulation, Mobility, Body Care and Movement, Social Interaction, Alertness, Emotional Behaviour, Behaviour, Communication, Sleep and Rest, Eating, Work, Home Management, Recreation and Pastimes. Each item is assigned a predetermined weight. Scores are calculated by summing the weights of all health related items and dividing by the maximum possible dysfunction score for each category. Scores are expressed as percentages, ranging from zero (no impairment) to 100 (maximum impairment).

Physical functioning was assessed by the GARS $[7,8]$. The GARS consists of 18 questions about daily activities, each with four response categories. Response choices range from 1) 'yes, I can do it fully and independently without any difficulty' to 4) 'no I cannot do it without someone's help'. The questionnaire comprises 11 items (scale range 11-44) referring to Activities in Daily Living (ADL, personal care) and seven items (scale range 7-28) to Instrumental Activities of Daily Living (IADL, household chores). The sum score provides information on the level of difficulty a person experiences in care taking and household activities. Sum scores may range from 18 (no disability) to 72 (maximum disability).

The following additional variables were assessed; age, gender, length of hospital stay, length of stay in Intensive Care Unit, discharge destination, pain and co-morbidity.

\section{Statistical analyses}

To test the unidimensional structure of the subscales of the questionnaires, principal components analysis was applied. Items in the principal components analysis with loading less than 0.4 were considered inadequately representative of the underlying dimension. Analyses were performed separately per subscale. In the analysis of the SIP-136, three items were excluded because no patients scored positive on these items. To further explore the correlation between the subscales of the SIP-136 and SF36 and GARS, the Spearman rank correlations between the subscale scores were calculated.

Internal consistency was investigated for all subscales of the SIP-136, SF-36 and GARS by calculating Cronbach's alpha $(\alpha)$.

Construct validity refers to the extent to which scores on a particular instrument relate to other measures in a manner that is consistent with theoretically derived hypotheses concerning the constructs that are being measured. To test the construct validity of the physical subscales of the SIP-136, SF-36 and GARS the following hypotheses were tested: HRQoL and functional status will be worse for 1) older patients, 2) patients with a longer hospital stay, 3) patients with a longer ICU stay, 4) patients who are discharged to other institutions instead of going home and 5) patients who experience more pain. Odds ratios (OR) and their 95\% confidence intervals (CIs) were calculated using logistic regression. In all regression analyses, age and co-morbidity were included as control variables.

\section{Results}

The characteristics of the study population are presented in table 1 . Table 2 contains the mean, standard deviation, median, score range and proportion minimum and maximum score (floor and ceiling effect) of the (sub) scales of the questionnaires. All domains of the SIP-136 were skewed towards higher (worse) values. Large percentages of patients scoring the minimum (best) score indicating a floor effect. Fewer ceiling effects were measured with the 
Table 1: Patient characteristics and clinical data measured 15 months after injury $(n=186)$

\begin{tabular}{|c|c|c|}
\hline \multicolumn{3}{|l|}{ Gender $\mathrm{n}(\%)$} \\
\hline Male & 139 & $(74.7)$ \\
\hline Female & 47 & $(25.3)$ \\
\hline Age (years), mean \pm SD (range) & $38.4 \pm 17.1$ & $(17-87)$ \\
\hline ISS mean \pm SD (range) & $24.5 \pm 10.8$ & $(16-66)$ \\
\hline Missing & 1 & \\
\hline Number of Surgery mean \pm SD (range) & $2.6 \pm 3.4$ & $(0-32)$ \\
\hline Missing & 3 & \\
\hline \multicolumn{3}{|l|}{ Length of stay (days), mean $\pm S D$ (range) } \\
\hline Intensive Care Unit & $6.7 \pm 14.2$ & $(0-123)$ \\
\hline Hospital & $27.9 \pm 24.2$ & $(1-153)$ \\
\hline \multicolumn{3}{|l|}{ Discharge destination n (\%) } \\
\hline Home & 126 & $(67.7)$ \\
\hline Rehabilitation Institution or Care Home & 60 & $(32.3)$ \\
\hline \multicolumn{3}{|l|}{ Co-morbidity n (\%) } \\
\hline None & 91 & $(48.9)$ \\
\hline One or more & 92 & $(49.5)$ \\
\hline Missing & 3 & \\
\hline Pain'1 mean \pm SD (range) & $3.0 \pm 1.3$ & $(1-6)$ \\
\hline
\end{tabular}

SF-36 than for the SIP-136. Four scales of the SF-36 were skewed towards lower (worse) values with relatively large numbers scoring the maximum value (ceiling effect) on three of those four scales. The GARS Total, ADL as well as the IADL were skewed towards higher (worse) values with large percentages of patients scoring the minimum (best) score.

Principal components analysis confirmed that the SF36 and GARS were unidimensional. The domains of the SF-36 showed eigenvalues ranging from 1.6 to 6.7 . The proportions of variance accounted for ranged from $51 \%$ to $89 \%$. All items loaded adequately on their respective subscales (loading > 0.40). For the ADL scale of the GARS, all 11 items loaded on one component (eigenvalue of 6.82, percentage of variance accounted for was 62\%). For the IADL score, also all items loaded on one component (eigenvalue of 5.3, percentage explained variance was $75.5 \%)$.

The unidimensionality of the SIP-136 was not supported. The 12 domains of the SIP-136 showed eigenvalues ranging from 1.9 to 6.0 . The percentages of variance accounted for ranged from 24.6-43.2. Only three subscales had a factor loading $>0.40$ of all items, whereas the other nine subscales had one or more (ranging from 1-12) items which were not loading on the scale $(<0.40)$.

Seven of the twelve subscales of the SIP-136 had a Cronbach's $\alpha$ higher than 0.70 . The other five subscales had relatively small number of constituent items in a scale. All subscales from the SF-36 exceed the minimum required value of 0.70 for group comparison. The Cronbach's $\alpha$ of the total score of the GARS and the two subscales of the GARS range from 0.94-0.96.

To test construct validity forty logistic regressions models were computed, controlling for age and co-morbidity. Thirty-eight hypotheses were supported $(\mathrm{p}<0.05)$ (table 3). The two not supported hypotheses concerned the SIP-136.

\section{Discussion}

The results of our study support the reliability (unidimensionality, internal consistency) and construct validity of the SF-36 and GARS in a polytrauma population with lower extremity injury. Whereas the construct validity of the SIP-136 in this population was supported, the unidimensionality and internal consistency of the subscales are not supported in the present study.

The analysis of the GARS showed that the ADL and IADL scales can be used as separate (unidimensional) scales but the strong association between the two scales indicated that the scales do not measure different aspects of functional outcome. Other studies $[7,11,12]$ also suggest one strong and reliable factor representing one underlying dimension of functional limitations.

Our study raises questions on the unidimensionality of most subscales of the SIP-136, suggesting that these subscales are not appropriate for use in a polytrauma population with injury of the lower extremity.

The internal consistency of the SIP-136 in the present study was low for most subscales. To our knowledge, little information about the internal consistency of the 12 separate scales of the SIP-136 is available in the literature. One study was found that reports sufficiently high Cronbach's $\alpha$ for the separate categories [13], while two other studies assessing the Cronbach's $\alpha$ of the subscales of the SIP-136 reported low Cronbach's [14,15]. High Cronbach's $\alpha$ from the total SIP-136 $[5,13,16]$ and the physical and psychological dimension scores are reported [13]. However, Cronbach's $\alpha$ is dependent on the number of items in a questionnaire, a high $\alpha$ coefficient of the sum scores of the SIP-136 is therefore not surprising and not informative.

Our findings supported the construct validity of the SF36 and GARS, these findings are comparable with the literature $[3,11,17,18]$. In our patient group, the construct 
Table 2: Features of the score distributions of the SIP-136, SF-36 and GARS scales $(n=186)$

\begin{tabular}{|c|c|c|c|c|c|c|c|}
\hline Instrument Scale & & Mean & SD & Median & Range $^{1}$ & Minimum $^{2}(\%)$ & Maximum $^{3}(\%)$ \\
\hline \multicolumn{8}{|l|}{ SIP-136 } \\
\hline & Ambulation & 17.32 & 17.8 & 15.3 & $0-67$ & 40.3 & 0.5 \\
\hline & Mobility & 6.76 & 13.6 & 0.0 & $0-60$ & 67.7 & 0.5 \\
\hline & Body Care and Movement & 5.92 & 10.1 & 1.5 & $0-55$ & 46.8 & 0.5 \\
\hline & Social Interaction & 7.73 & 13.2 & 0.0 & $0-73$ & 52.2 & 0.5 \\
\hline & Alertness & 12.69 & 20.9 & 0.0 & $0-97$ & 59.7 & 0.5 \\
\hline & Emotional Behaviour & 8.76 & 15.3 & 0.0 & $0-91$ & 60.8 & 0.5 \\
\hline & Communication & 4.08 & 9.8 & 0.0 & $0-53$ & 80.1 & 0.5 \\
\hline & Sleep and Rest & 9.46 & 13.8 & 0.0 & $0-78$ & 54.3 & 0.5 \\
\hline & Eating & 1.91 & 5.3 & 0.0 & $0-31$ & 83.3 & 1.1 \\
\hline & Work & 26.96 & 31.5 & 8.4 & $0-70$ & 41.9 & 2.7 \\
\hline & Home Management & 14.23 & 19.8 & 6.6 & $0-82$ & 45.7 & 0.5 \\
\hline & Recreation and Pastimes & 15.55 & 17.5 & 10.2 & $0-72$ & 40.3 & 0.5 \\
\hline \multicolumn{8}{|l|}{ SF-36 } \\
\hline & Physical Functioning & 62.90 & 29.6 & 65.0 & $0-100$ & 2.7 & 12.4 \\
\hline & Role-Physical & 53.20 & 42.7 & 50.0 & $0-100$ & 30.1 & 36.6 \\
\hline & Bodily Pain & 70.30 & 25.1 & 68.4 & $0-100$ & 0.5 & 25.3 \\
\hline & General Health & 67.10 & 20.6 & 70.0 & $10-100$ & 1.1 & 2.7 \\
\hline & Vitality & 62.40 & 19.1 & 65.0 & $0-100$ & 0.5 & 1.6 \\
\hline & Social Functioning & 74.80 & 28.2 & 87.5 & $0-100$ & 4.3 & 34.9 \\
\hline & Role-Emotional & 78.30 & 36.7 & 100 & $0-100$ & 12.9 & 70.4 \\
\hline & Mental Health & 74.30 & 19.6 & 80.0 & $12-100$ & 0.5 & 4.3 \\
\hline \multicolumn{8}{|l|}{ GARS } \\
\hline & Totaal & 25.70 & 11.5 & 19.5 & $18-71$ & 44.1 & 1.1 \\
\hline & $\mathrm{ADL}$ & 14.50 & 6.0 & 11.0 & $11-43$ & 51.6 & 1.6 \\
\hline & IADL & 11.20 & 5.9 & 8.0 & $7-28$ & 48.9 & 2.2 \\
\hline
\end{tabular}

SIP-136 = Sickness Impact Profile-136; SF-36 = SF-36 item Health Status Survey; GARS = Groningen

Activity Restriction Scale; ADL = Activities in Daily Living; IADL = Instrumental Activities of Daily Living;

$\mathrm{n}=$ number; $\mathrm{SD}=$ standard deviation.

1 Patients score range, minimum and maximum score.

2 Percentage of patients with minimum score, floor effect.

3 Percentage of patients with maximum score, ceiling effect.

validity of the SIP-136 was supported to a lower extent. Ho et al [16] found an advantage in using the SF-36 above the SIP because of its more robust construct validity, while others found some evidence to support the construct validity of the SIP $[13,15,19]$.

The present study gives information about internal consistency and construct validity but does not provide information about other psychometric properties such as sensitivity to change over time and test-retest reliability.
Additionally, other instruments may be suitable for this study population. Based on our results, further psychometric testing of the SF-36 and GARS in this population is recommended.

\section{Conclusion}

The SF-36 and the GARS appear to be preferable for use in polytrauma patients over the SIP- 136 . 
Table 3: Associations between patient characteristics and functional status and HRQoL 15 months after injury

\begin{tabular}{|c|c|c|c|c|c|c|c|}
\hline & & \multicolumn{3}{|c|}{ Age } & \multicolumn{3}{|c|}{ Hospital stay } \\
\hline & & OR & $95 \% \mathrm{Cl}$ & $P$ & OR & $95 \% \mathrm{Cl}$ & $P$ \\
\hline \multirow[t]{4}{*}{ SIP-136 } & Body Care and Movement $* *$ & 1.33 & $0.72-2.45$ & 0.179 & 1.95 & $1.06-3.58$ & 0.016 \\
\hline & Home Management * & 2.30 & $1.60-5.62$ & 0.001 & 4.58 & $2.32-9.04$ & 0.000 \\
\hline & Mobility * & 1.81 & $0.94-3.50$ & 0.039 & 4.78 & $2.32-9.84$ & 0.000 \\
\hline & Ambulation * & 1.82 & $0.99-3.35$ & 0.028 & 3.21 & $1.71-6.02$ & 0.000 \\
\hline \multirow[t]{2}{*}{ SF-36 } & Role-Physical ** & 0.44 & $0.24-0.82$ & 0.005 & 0.34 & $0.18-0.64$ & 0.001 \\
\hline & Physical Functioning * & 0.35 & $0.18-0.66$ & 0.001 & 0.16 & $0.08-0.33$ & 0.000 \\
\hline \multirow[t]{4}{*}{ GARS } & $\mathrm{ADL}^{*}$ & 3.33 & $1.75-6.35$ & 0.000 & 3.77 & $1.90-7.48$ & 0.000 \\
\hline & $\operatorname{IADL} * *$ & 3.16 & $1.68-5.95$ & 0.000 & 6.55 & $3.19-13.46$ & 0.000 \\
\hline & & \multicolumn{3}{|c|}{ Intensive care stay } & \multicolumn{3}{|c|}{ Discharge destination } \\
\hline & & OR & $95 \% \mathrm{Cl}$ & $P$ & OR & $95 \% \mathrm{Cl}$ & $P$ \\
\hline \multirow[t]{4}{*}{ SIP-136 } & Body Care and Movement $* *$ & 1.26 & $0.69-2.30$ & 0.228 & 2.29 & $1,17-4,50$ & 0,008 \\
\hline & Home Management * & 2.79 & $1.43-5.42$ & 0.002 & 3.36 & $1,64-6,87$ & 0,001 \\
\hline & Mobility * & 3.01 & $1.51-6.02$ & 0.001 & 3.08 & $1,53-6,22$ & 0,001 \\
\hline & Ambulation * & 1.70 & $0.92-3.17$ & 0.046 & 2.06 & $1,04-4,06$ & 0,019 \\
\hline \multirow[t]{2}{*}{ SF-36 } & Role-Physical ** & 0.51 & $0.27-0.95$ & 0.018 & 0.36 & $0,18-0,72$ & 0,002 \\
\hline & Physical Functioning * & 0.35 & $0.18-0.68$ & 0.001 & 0.31 & $0,15-0,62$ & 0,001 \\
\hline \multirow[t]{4}{*}{ GARS } & $A D L *$ & 1.86 & $0.96-3.60$ & 0.034 & 4.41 & $2,05-9,46$ & 0,000 \\
\hline & IADL ** & 2.83 & $1.45-5.51$ & 0.001 & 4.74 & $2,28-9,87$ & 0,000 \\
\hline & & \multicolumn{3}{|c|}{ Pain } & & & \\
\hline & & OR & $95 \% \mathrm{Cl}$ & $P$ & & & \\
\hline \multirow[t]{4}{*}{ SIP-136 } & Body Care and Movement ${ }^{* *}$ & 6.25 & $3.04-12.84$ & 0.000 & & & \\
\hline & Home Management * & 7.05 & $3.29-15.13$ & 0.000 & & & \\
\hline & Mobility * & 4.72 & $2.33-9.56$ & 0.000 & & & \\
\hline & Ambulation * & 8.73 & $4.00-19.08$ & 0.000 & & & \\
\hline \multirow[t]{2}{*}{ SF-36 } & Role-Physical ** & 0.10 & $0.04-0.23$ & 0.000 & & & \\
\hline & Physical Functioning * & 0.17 & $0.08-0.34$ & 0.000 & & & \\
\hline \multirow[t]{2}{*}{ GARS } & $A D L *$ & 7.22 & $3.25-16.02$ & 0.000 & & & \\
\hline & IADL ** & 5.72 & $2.74-11.95$ & 0.000 & & & \\
\hline
\end{tabular}

SIP-136 = Sickness Impact Profile- 136; SF-36 = SF-36 item Health Status Survey; GARS = the Groningen Activity Restriction Scale; ADL = Activities in Daily Living; IADL = Instrumental Activities of Daily Living; $\mathrm{OR}=$ Odds Ratio; $\mathrm{Cl}=$ Confidence Interval.

${ }^{*}$ Adjusted for co-variates: age, gender and co-morbidity.

${ }^{* *}$ Adjusted for co-variates: age and co-morbidity.

\section{Competing interests}

The authors declare that they have no competing interests.

\section{Authors' contributions}

$L$, MPMS and JD designed the study. $L J$ reviewed the literature and $\mathrm{HRH}$ collected all data.

$L$, MPMS and JD contributed to the analysis and interpretation of data which was initially performed by $L$. $L J$ drafted the manuscript, supported by MPMS. JD supervised and JD and GK reviewed the manuscript thoroughly for intellectual content.

\section{Author Details}

1Department of Allied Health Care, St Antonius Hospital, Nieuwegein, The Netherlands, ${ }^{2}$ Department of Rehabilitation Medicine and EMGO Institute, VU University Medical Centre, Amsterdam, The Netherlands, ${ }^{3}$ Institute of Health and Wellbeing, Caledonian University, Glasgow, UK and ${ }^{4}$ University Medical Centre Utrecht, The Netherlands

Received: 8 March 2010 Accepted: 28 June 2010 Published: 28 June 2010 


\section{References}

1. Richmond TS, Kauder D, Hinkle J, Shults J: Early predictors of long-term disability after injury. Am J Crit Care 2003, 12:197-205.

2. DePalma JA, Fedorka P, Simko LC: Quality of life experienced by severely injured trauma survivors. AACN Clin Issues 2003, 14:54-63.

3. Stalp M, Koch C, Ruchholtz S, Regel G, Panzica M, Krettek C, et al. Standardized outcome evaluation after blunt multiple injuries by scoring systems: a clinical follow-up investigation 2 years after injury. $J$ Trauma 2002, 52:1160-1168.

4. Van der Sluis CK, Eisma WH, Groothoff JW, ten Duis HJ: Long-term physical, psychological and social consequences of a fracture of the ankle. Injury 1998, 29:277-280.

5. Bergner M, Bobbitt RA, Carter WB, Gilson BS: The Sickness Impact Profile: development and final revision of a health status measure. Med Care 1981, 19:787-805.

6. Ware J, Snow K, Kosinski M, Gandek B: SF-36 Health Survey. Manual and Interpretation guide. Boston: MA; 1993.

7. Kempen Gl, Miedema I, Ormel J, Molenaar W: The assessment of disability with the Groningen Activity Restriction Scale. Conceptual framework and psychometric properties. Soc Sci Med 1996, 43:1601-1610.

8. Kempen GIJM, Doeglas DM, Suurmeijer TPBM: Het meten van problemen met zelfredzaamheid op verzorgend en huishoudelijk gebied met de Groningen Activiteiten Restrictie Schaal (GARS). Een handleiding. Groningen The Netherlands: Northern Centre for Health Care Research; 1993.

9. Holtslag HR, van Beeck EF, Lindeman E, Leenen LP: Determinants of longterm functional consequences after major trauma. J Trauma 2007, 62:919-927.

10. Werkman HA, ten Vergert EM, Kingma J, ten Duis HJ: Comparison of 2 scales in the assessment of injury severity in seriously injured patients. Ned Tijdschr Geneeskd 1992, 136:1162-1166.

11. Suurmeijer TP, Doeglas DM, Moum T, Briancon S, Krol B, Sanderman R, et al:: The Groningen Activity Restriction Scale for measuring disability: its utility in international comparisons. Am J Public Health 1994, 84:1270-1273

12. Hsueh IP, Wang WC, Sheu CF, Hsieh CL: Rasch analysis of combining two indices to assess comprehensive ADL function in stroke patients. Stroke 2004, 35:721-726.

13. De Bruin AF, de Witte LP, Stevens F, Diederiks JP: Sickness Impact Profile: the state of the art of a generic functional status measure. Soc Sci Med 1992, 35:1003-1014.

14. Rothman ML, Hedrick S, Inui T: The Sickness Impact Profile as a measure of the health status of noncognitively impaired nursing home residents. Med Care 1989, 27(Suppl 3):157-167.

15. Essink-Bot ML, Krabbe PF, van Agt HM, Bonsel GJ: NHP or SIP--a comparative study in renal insufficiency associated anemia. Qual Life Res 1996, 5:91-100.

16. Ho AK, Robbins AO, Walters SJ, Kaptoge S, Sahakian BJ, Barker RA: Healthrelated quality of life in Huntington's disease: a comparison of two generic instruments, SF-36 and SIP. Mov Disord 2004, 19:1341-1348.

17. Hagen S, Bugge C, Alexander H: Psychometric properties of the SF-36 in the early post-stroke phase. J Adv Nurs 2003, 44:461-468

18. Failde I, Ramos I: Validity and reliability of the SF- 36 Health Survey Questionnaire in patients with coronary artery disease. $J$ Clin Epidemiol 2000, 53:359-65.

19. Thomas K, Ruby J, Peter JV, Cherian AM: Comparison of disease-specific and a generic quality of life measure in patients with bronchial asthma. Nat/Med J India 1995, 8:258-260.

doi: 10.1186/1752-2897-4-7

Cite this article as: Jansen et al., Psychometric properties of questionnaires evaluating health-related quality of life and functional status in polytrauma patients with lower extremity injury Journal of Trauma Management \& Outcomes 2010, $4: 7$

\section{Submit your next manuscript to BioMed Central} and take full advantage of:

- Convenient online submission

- Thorough peer review

- No space constraints or color figure charges

- Immediate publication on acceptance

- Inclusion in PubMed, CAS, Scopus and Google Scholar

- Research which is freely available for redistribution 